\title{
Effects of Qualea grandiflora Extract on the Expression of MMP-14 and HIF-1 $1 \alpha$ in Cultured Fibroblasts and Preosteoblasts
}

Gabriela Silva Neubern de Oliveira ${ }^{1}$

https://orcid.org/0000-0003-0037-5665

Cintia Kazuko Tokuhara ${ }^{1}$

https://orcid.org/0000-0002-1852-5986

Flávia Amadeu de Oliveira ${ }^{1}$

https://orcid.org/0000-0003-3063-6694

\section{Márcia Sirlene Zardin Graeff ${ }^{1}$}

https://orcid.org/0000-0002-6854-7913

\section{Zohaib Nisar Khan ${ }^{1}$}

https://orcid.org/0000-0001-9233-8639

1University of São Paulo, Bauru School of Dentistry, Department of Biological Sciences. Bauru, São Paulo, Brazil; ${ }^{2}$ São Paulo State University, Faculty of Sciences, Department of Biological Sciences. Bauru, São Paulo, Brazil.

Editor-in-Chief: Alexandre Rasi Aoki

Associate Editor: Sinvaldo Baglie

Received: 2020.11.11; Accepted: 2021.10.15.

*Correspondence: rodrigocardoso@usp.br. Tel: (55) 1432358247 (R.C.O.).

\section{HIGHLIGHTS}

- Qualea grandiflocompounds with proven therapeutic properties;

- Hydroalcoholic extract of the leaves of Qualea grandiflora increase the expression of MMP-14 and HIF-1a.

Abstract: Background: Qualea grandiflora (QG) (Vochysiaceae), also known as "pau-ferro", "pau-terra" or "pau-de-tucano", is a very common deciduous tree in the Brazilian Cerrado used in traditional medicine to treat inflammations, ulcers, diarrhea, and infections. There are reports in the scientific literature that demonstrate the medicinal effects of the bark and leaf of the QG. However, studies involving this plant are rather imited. Aim of the study: To perform the phytochemical analysis of the QG hydroalcoholic extract (HAE) of leaves, and to investigate it effects on fibroblast and preosteoblasts. Methods: Phytochemical analysis was done by HPLC-DAD. Murine NIH/3T3 fibroblasts and MC3T3-E1 preosteoblasts cell lines (ATCC) were used for the experiments. Cell viability was assessed by the MTT colorimetric assay and the expression of MMP14 and HIF-1a by immunofluorescence. Results and conclusion: The following compounds were identified by HPLC-DAD, such as quinic acid, ethyl galate, ellagic acid derivatives as O-methylellagic acid O-galloyl, O-methylellagic acid O-deoxyhexoside, galloyl derivatives, flavonol glycoside as kaempferol-Odeoxyhexoside, quercetin-O-deoxyhexoside, myricetin-O-deoxyhexoside and the pentacyclic triterpene arjunglucoside. Cell viability results demonstrated no cytotoxic effects in the studied concentrations. We 
found in QG HAE some compounds with therapeutic properties that can increase the expression of MMP-14 and HIF-1a, in fibroblasts and preosteoblasts. These data suggest that QG HAE has an action on these two molecules widely involved in physiological conditions, such as collagen remodeling, bone development and growth and pathological processes as HIF signaling in cancer metastasis.

Keywords: Qualea grandiflora; Hypoxia-inducible factor 1-alpha; Matrix Metalloproteinase-14; Medicinal plant; Vochysiaceae.

\section{INTRODUCTION}

Qualea grandiflora Mart. (QG), a large tree belonging to the Vochysiaceae family is one of the most common tree species in the Brazilian Cerrado [1]. Many studies using QG extracts have reported several therapeutic aspects such as the cure and prevention of gastric mucosa damage, central nervous system depressant, analgesic effect, anticonvulsant, anti-inflammatory, antimicrobial, and active in the treatment of wounds $[2,3,4,5,6]$. These researches show that the $Q G$ has components with important pharmacological activities, however, studies involving the plant in question are still scarce. Phytochemical studies of the QG bark include triterpenoids and polyphenols derived from flavonoids, gallic, and ellagic acids [7, 8]. Flavonoids, polyphenols, and gallate molecules have been researched due to biological activities with antioxidant, antiinflammatory, and anti-cancerous function [9, 10].

The "Hypoxia-inducible factor 1-alpha" (HIF-1 $\alpha$ ) and the "Matrix Metalloproteinase 14" (MMP-14) are two molecules closely related to different physiological processes and, for example, angiogenesis can be mentioned. In a situation like a wound healing, a greater amount of oxygen is required, and angiogenesis is triggered. This process is important for the formation of new blood vessels and happens through intense interaction between a wide variety of molecules which include MMP-14 and HIF- $\alpha[11,12,13,14]$. Experimental studies suggest that an increase in the vascular remodeling system improves the blood supply and, consequently, tissue repair. Studies related to bone regeneration show that, in the early stages of the process, HIF- $\alpha$ is activated and that the peak expression of this factor suggests that it regulates one or more processes related to repair [15].

Given the fact that the $Q G$ extract has important properties related to the modulation of physiological processes and that MMP-14 and HIF- $\alpha$ are closely related and involved in tissue repair, we investigated in the present study, the phytochemical properties of the hydroalcoholic extract (HAE) of QG and its role on MMP-14 and HIF-1 $\alpha$ expression and distribution as well as its effects on fibroblasts NIH-3T3 and preosteoblasts MC3T3-E1viability.

\section{MATERIAL AND METHODS}

\section{Preparation of the extract}

Samples of QG fresh leaves were harvested in October 2013 on the campus of the University of São Paulo State (UNESP) - Bauru, São Paulo, Brazil. A voucher specimen was prepared, identified by A. L. Dokkedal, and deposited in the Herbarium (UNBA) (identification number 6034) of the College of Sciences at University of São Paulo State (UNESP), Bauru, São Paulo, Brazil. The leaves were hot air-dried at $60{ }^{\circ} \mathrm{C}$ and grounded in a knife mill (Marconi; Piracicaba, São Paulo, Brazil). The dried and powdered leaves were extracted via percolation with $\mathrm{EtOH}: \mathrm{H}_{2} \mathrm{O}(7: 3, \mathrm{v} / \mathrm{v})$ at room temperature.

The obtained hydroalcoholic solution was concentrated in a rotary evaporator (Heidolph; Schwabach, Bavaria, Germany) under reduced pressure at $40{ }^{\circ} \mathrm{C}$. These processes yield $20 \mathrm{~g}(20 \%)$ of the EtOH $70 \%$ extract of the leaves of QG. To carry out the experiments, the hydroalcoholic extract was directly diluted in the culture medium (DMEM or a-MEM), supplemented with $10 \%$ fetal bovine serum (FBS - Gibco-BRL, Grand Island, NY, USA) and 1\% penicillin/streptomycin. From this solution, the following dilutions $0.1,1.0$, and 10.0 $\mu \mathrm{g} / \mathrm{ml}$ were made. The vehicle was used as a positive control. Due to antimicrobial properties reported in the literature, the extract was not filtered as this could remove important active compounds of the plant (5).

\section{Phytochemical analysis}

The phytochemical analysis of the QG extract was performed in an HPLC 1200 Series (Agilent; Santa Clara, CA, USA), with autosampler 1200 Series coupled to diode array detector (DAD) 1260 and mass 
spectrometer detector 3200 equipped with Quadrupole-linear lon Trap (QTRAP) and ionization by electrospray (ESI). The chromatographic separations were performed using C18 (250x4.6 mm i.d.; $5 \mu \mathrm{m})$ column (Phenomenex; Torrance, CA, USA) conditioned in column oven 1200 Series at $35^{\circ} \mathrm{C}$. The following parameters were used for the analysis in negative mode: Ion Spray: $-4500 \mathrm{~V}$, Curtain Gas:20 psi, Temperature: $650^{\circ} \mathrm{C}$, Gas 1: $50 \mathrm{psi}$, Gas 2: $50 \mathrm{psi}$, Interface heater: ON, DP (Declustering Potential) $-25.0 \mathrm{~V}$, EP (Entrance Potential) -10.0 V e CEP (Cell entrance potential) -16.0 V. Enhanced Scan mode (EMS): 100 - $800 \mathrm{Da}$. EPI (Enhanced production) Collision energy was adjusted to $35.0 \mathrm{~V}+/-15.0 \mathrm{~V}$.

\section{Cell Culture}

Murine NIH/3T3 fibroblasts (ATCC) and MC3T3-E1 preosteoblasts (ATCC) cell lines were cultivated in Dulbecco's Modified Eagle Medium (DMEM - Sigma-Aldrich, St. Louis, MO, USA) and Minimum Essential Medium Eagle - Alpha Modification (a-MEM - Sigma-Aldrich, St. Louis, MO, USA), respectively, and supplemented with $10 \%$ fetal bovine serum (FBS) and $1 \%$ penicillin/streptomycin. Cells were incubated at $37^{\circ} \mathrm{C}$ in a humid atmosphere containing $5 \% \mathrm{CO}_{2}[16,17]$.

\section{MTT assay}

For viability assay, $3 \times 10^{3}$ cells/well were plated in 96 -well plates. After $24 \mathrm{~h}$ of incubation, cells were treated with $0.1,1.0$, and $10 \mu \mathrm{g} / \mathrm{ml}$ of $Q G$ crude hydroalcoholic extract for $24,48,72$, and $96 \mathrm{~h}$ time points [18]. Positive and negative control groups were also carried out, the cells being treated, respectively, with culture medium $+10 \%$ FBS and culture medium $+1 \%$ FBS medium. Control groups were not exposed to the extract. After treatment times, the MTT (Sigma-Aldrich, St. Louis, MO, USA) assay was performed according to the method of Mosmann [19]. The purplish-blue formazan was solubilized in dimethyl sulfoxide (DMSO) $(200 \mu l)$. (Labsynth, São Paulo, Brazil) and its concentration was determined by the optical density (OD) in a spectrophotometer at 570nm (Fluostar OPTIMA, BMG Labtech, Offenburg, Germany) [20]. Biological and experimental triplicates were performed $(n=9)$.

\section{Immunofluorescence Staining}

To assess the MMP-14 and HIF-1 $\alpha$ expression, $1 \times 10^{4}$ cells/well were plated in 24-well plates containing coverslips. After 24, 48, 72, and 96h of treatment, cells were washed with PBS, and fixed in $100 \%$ methanol (JT Baker, Phillipsburg, NJ, USA) for $6 \mathrm{~min}$ at $4^{\circ} \mathrm{C}$ and then washed with PBS. Next, cells were washed $3 x$ with $0.1 \%$ PBS-Tween for five minutes each (Sigma-Aldrich, St. Louis, MO, USA), and then they were permeabilized with $0.05 \%$ Triton X-100 (Sigma-Aldrich, St. Louis, MO, USA) for 10 minutes at $4^{\circ} \mathrm{C}$, followed by other subsequential washes with $0.1 \%$ PBS-Tween. To block the nonspecific sites, $5 \%$ skimmed MOLICO® milk was added to the cells for 30 minutes. The samples were incubated with the primary antibody - Anti-MMP14 Rabbit Polyclonal Antibody (1:250) (sc-30074, Santa Cruz Biotechnology, Inc, Santa Cruz, CA, USA) and Anti-HIF-1a Rabbit Polyclonal Antibody (1:250) (sc-10790, Santa Cruz Biotechnology, Inc, Santa Cruz, CA, USA) overnight at $4^{\circ} \mathrm{C}$. Then, the cells were washed $3 x$ with PBS-Tween for 10 minutes each. Skimmed MOLICO® milk at $1 \%$ was added for 15 minutes and, after that, the cells were incubated with mouse anti-rabbit IgG-PE secondary antibody (sc-3753, Santa Cruz Biotechnology, Inc, Santa Cruz, CA, USA) or mouse anti-rabbit IgG-FITC secondary antibody (sc- 2359, Santa Cruz Biotechnology, Inc, Santa Cruz, CA, USA) (1:250) for $1 \mathrm{~h} 30$ min at room temperature. Next, the samples were washed $3 \mathrm{x}$ in $0.1 \%$ PBSTween for 10 minutes each. Prolong gold (Life technologies, Foster City, CA, USA) was added onto glass slides, on which the coverslips were placed and subsequently examined by the fluorescence confocal microscope (DMIRB; Leica, Wetzlar, Hesse, Germany).

The positive control group means the presence of the primary and secondary antibodies, and the negative control consisted of the absence of primary antibody. Osteosarcoma cells (SaOS-2, ATCC; Washington, DC, USA) were used as a positive control for labeling since they have high expression of MMP14 and HIF-1 $\alpha$ [21, 22].

\section{Statistical analysis}

The data were presented as a percentage of the mean and standard deviation (SD). The parameters were analyzed by One-Way ANOVA followed by Tukey's posthoc test. P values $<0.05$ were considered statistically significant. All statistical tests were performed using GraphPad InStat and Prisma (GraphPad, San Diego, CA, USA). 


\section{RESULTS}

\section{Phytochemical analysis}

The phytochemical characterization of the QG extract by LC-MS/MS ${ }^{n}$ allowed the dereplication of ellagic acid derivatives, flavonols, and a pentacyclic triterpene based on the retention time and MS/MS data (Table $\mathrm{S} 1$, Supplementary Information). It was possible to tentatively identify quinic acid (1), ethyl galate (2), ellagic acid derivatives as O-methylellagic acid O-galloyl (3-4), O-methylellagic acid O-deoxyhexoside (10), galloyl derivatives $(7,13)$, flavonol glycoside as kaempferol-O-deoxyhexoside (11), quercetin-O-deoxyhexoside (8), myricetin-O-deoxyhexoside (6) and the pentacyclic triterpene arjunglucoside (14). There were no previous reports of flavonols derivatives in the leaves of $Q$. grandiflora.

\section{MTT assay}

Figures 1 and 2 show the effect of the different concentrations $(0.1,1.0$, and $10 \mu \mathrm{g} / \mathrm{ml})$ of the QG HAE on fibroblasts and preosteoblasts viability, respectively, up to 96 hours of exposure. NIH-3T3 viability was significantly decreased at 72 and $96 \mathrm{~h}$ after exposure with $10 \mu \mathrm{g} / \mathrm{ml}$ of QG HE when compared to the positive control. The positive control was used as a comparison parameter representing $100 \%$ of cellular viability ( $P$ $<0.05$ ) (Figure 1).

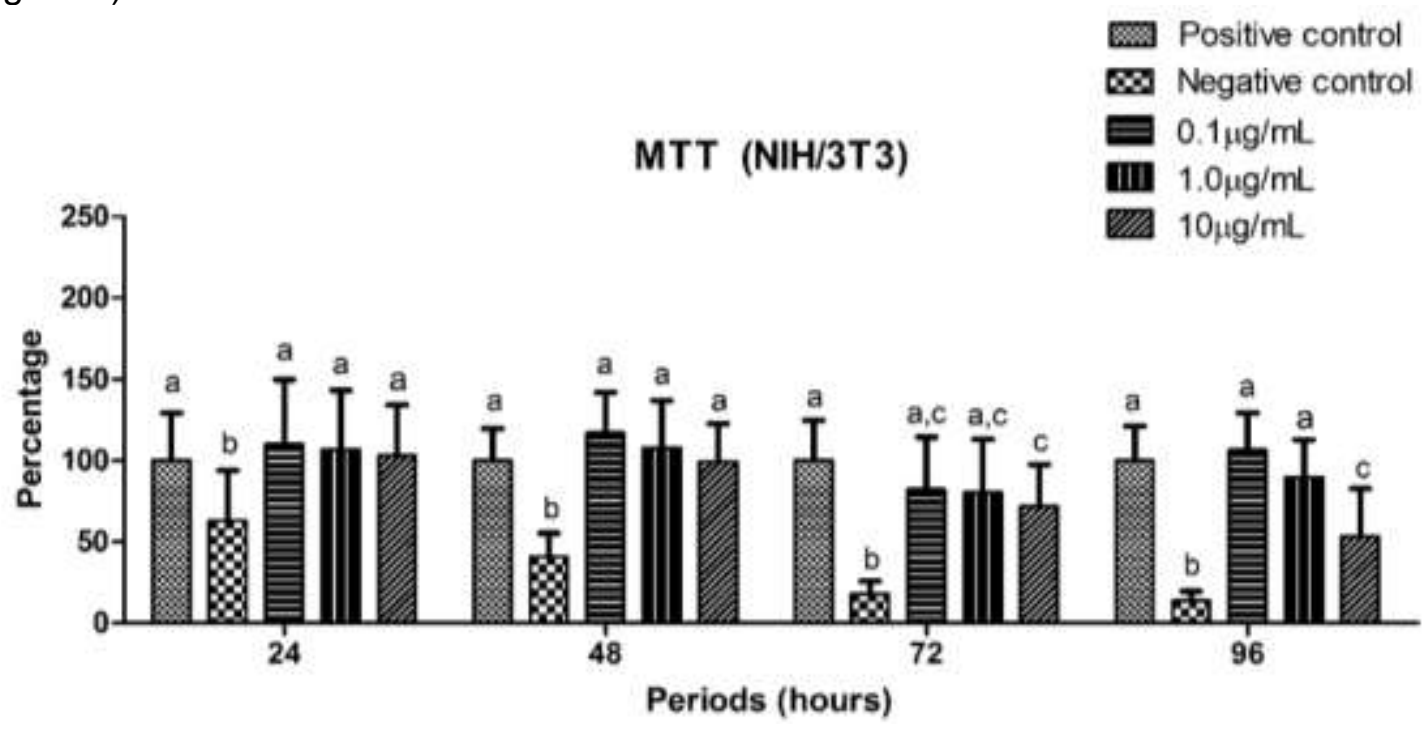

Figure 1. Effects of the QG HAE at different concentrations $(0.1,1.0$ and $10 \mu \mathrm{g} / \mathrm{ml})$ on $\mathrm{NIH} / 3 \mathrm{~T} 3$ fibroblasts viability by MTT assay at 24, 48, 72, and 96 hours. Different letters $(a, b$, and $c)$ indicate differences statistically significant $(P<0.05)$ within each period. Vertical bars represent standard deviation. The parameters were analyzed by One-Way ANOVA followed by Tukey's posthoc test. $Q G=$ Qualea grandiflora; HAE = hydroalcoholic extract; Positive control = cells exposed to DMEM $+10 \%$ fetal bovine serum; Negative control $=$ cells exposed to DMEM $+1 \%$ fetal bovine serum.

Results from MC3T3-E1 cells showed an increase of cell viability after $96 \mathrm{~h}$ of treatment, in the concentration of $0.1 \mu \mathrm{g} / \mathrm{ml}$ and a decrease in the concentration of $10 \mu \mathrm{g} / \mathrm{ml}$ when compared with the positive control (No treatment added. Used as a comparison parameter $-100 \%$ cellular viability) $(P<0.05)$ (Figure 2 ). 
MTT (MC3T3-E1)

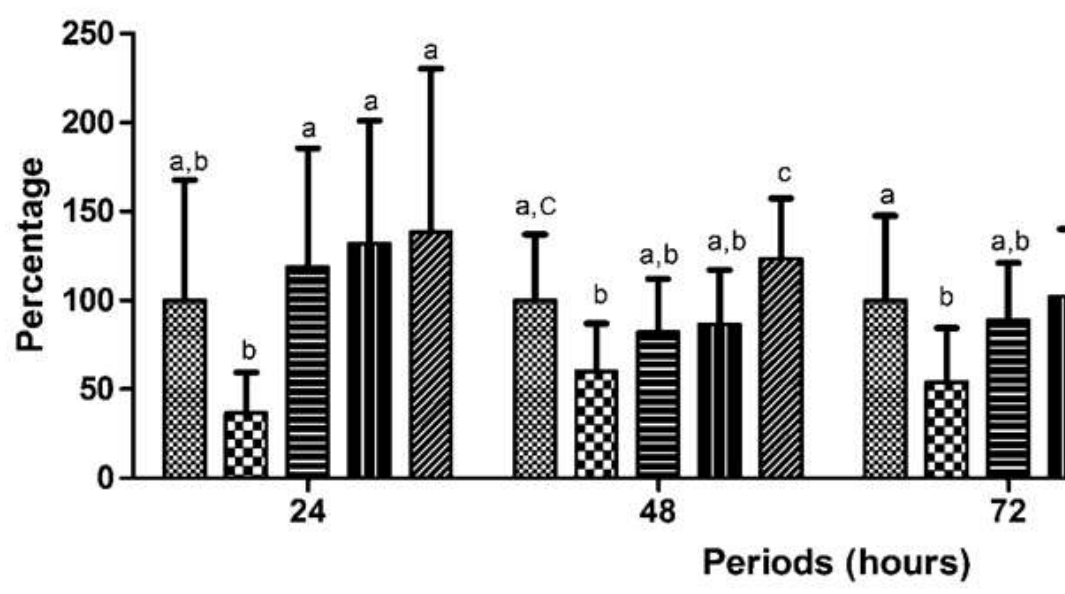

Positive control

Negative control

$0.1 \mu \mathrm{g} / \mathrm{mL}$

IIII $1.0 \mu \mathrm{g} / \mathrm{mL}$

UII $10 \mu \mathrm{g} / \mathrm{mL}$

Figure 2. Effect of the QG HAE at different concentrations $(0.1,1.0$ and $10 \mu \mathrm{g} / \mathrm{ml})$ on MC3T3-E1 preosteoblasts viability by MTT assay at $24,48,72$, and $96 \mathrm{~h}$. Different letters (a, b, and c) indicate differences statistically significant $(P<0.05)$ within each period. Vertical bars represent standard deviation. The parameters were analyzed by One-Way ANOVA followed by Tukey's posthoc test. QG = Qualea grandiflora; HAE = hydroalcoholic extract; Positive control = cells exposed to DMEM + 10\% fetal bovine serum; Negative control = cells exposed to DMEM $+1 \%$ fetal bovine serum.

\section{Immunofluorescence}

Figures 3 and 4 demonstrate the effect of the highest concentration $(10 \mu \mathrm{g} / \mathrm{ml})$ of the QG HAE on the expression of MMP-14 and HIF-1 $\alpha$ after 24 and 96h, in NIH/3T3 and MC3T3-E1 cells. The images related to the labeling of the proteins exposed to the other dilutions $(0.1$ and $1.0 \mu \mathrm{g} / \mathrm{ml})$ and periods (48 and $72 \mathrm{~h})$ are not shown, as they presented similarity to the positive control group (untreated).

The results showed an increase of MMP-14 and HIF-1 $\alpha$ expression in NIH/3T3 fibroblasts (Figure 3 ) and MC3T3-E1 preosteoblasts (Figure 4) in a time-dependent manner at the highest concentration $(10 \mu \mathrm{g} / \mathrm{ml})$ comparing with the non-treated groups and with the control cells (SaOS-2). In general, MMP-14 and HIF-1a were localized in the cytosol.

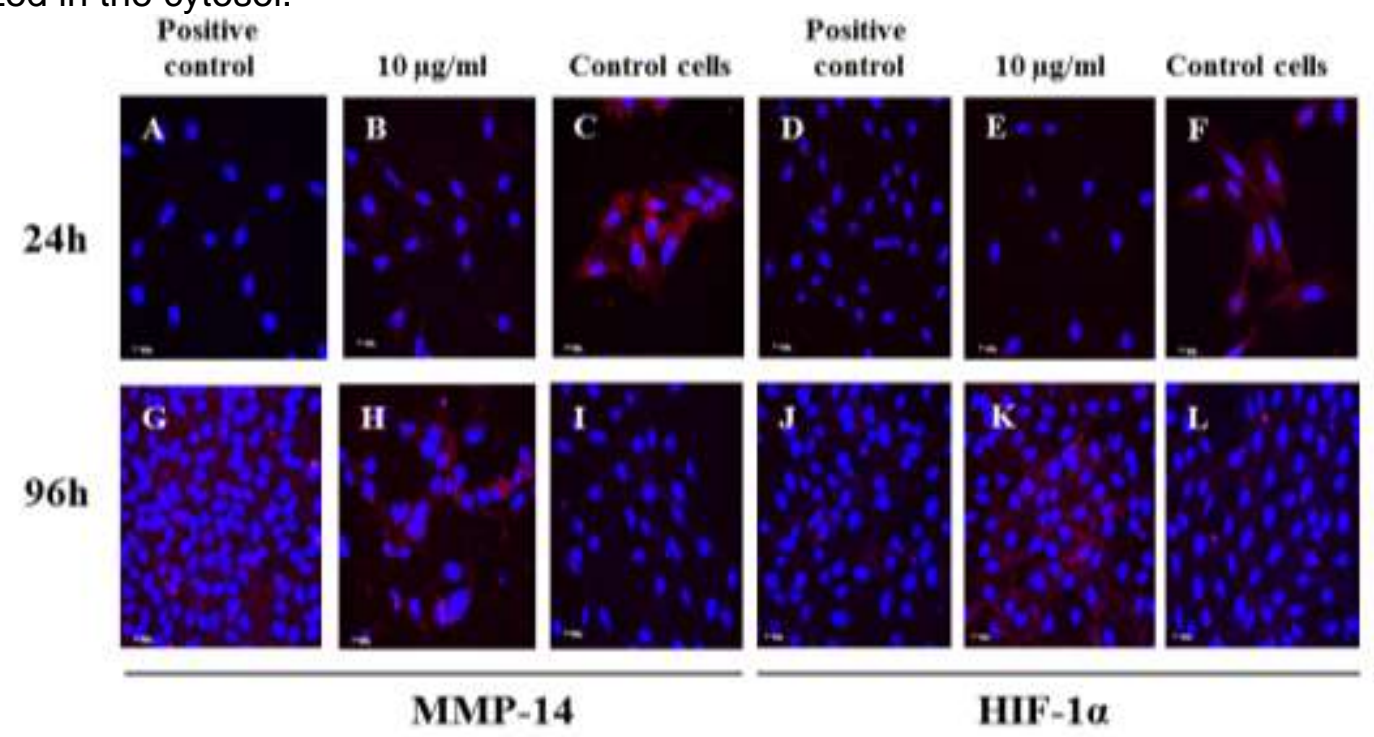

Figure 3. Effects of the QG HAE on the expression of MMP-14 (A, B, C, G, H, and I) and HIF-1a (D, E, F, J, K) in $\mathrm{NIH} / 3 \mathrm{~T} 3$ fibroblasts by immunofluorescence. Results indicate that NIH/3T3 fibroblasts treated with QG $(10 \mu \mathrm{g} / \mathrm{ml})$ showed increased expression of MMP-14 $(\mathrm{H})$ and HIF-1 $\alpha(\mathrm{K})$ when compared to the positive control group (untreated) at $96 \mathrm{~h}(\mathrm{G}$ and $\mathrm{J})$. Cells with red immunofluorescence (white arrow) are visible on fibroblasts treated with QG (H and K) and antibody control ( $\mathrm{C}$ and $\mathrm{F}$ ). Control cells (SaOS-2): the presence of primary antibody ( $\mathrm{C}$ and $\mathrm{F})$ and the absence of primary antibody (I and L). The nuclei were stained with DAPI (blue). Scale bar: $20 \mu \mathrm{m}$. 40X magnification. 


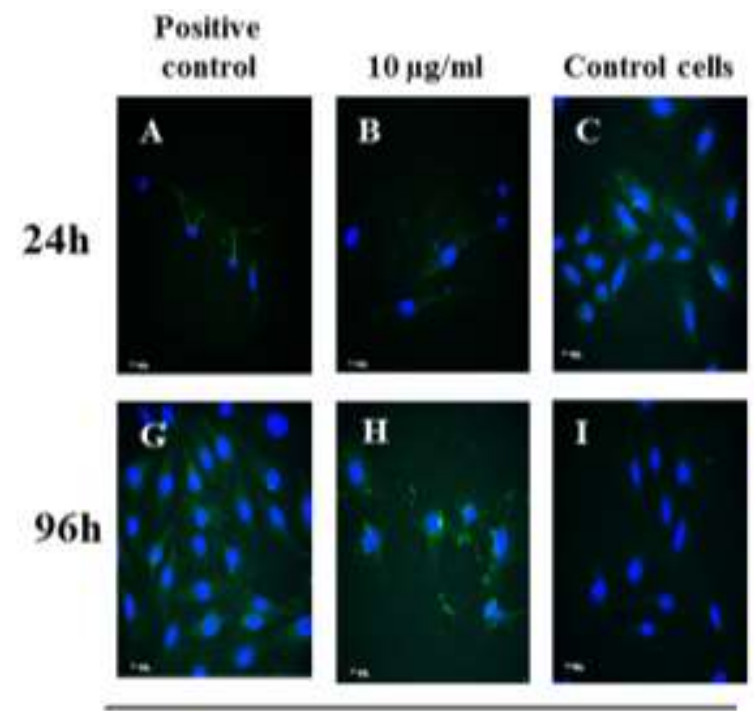

MMP-14

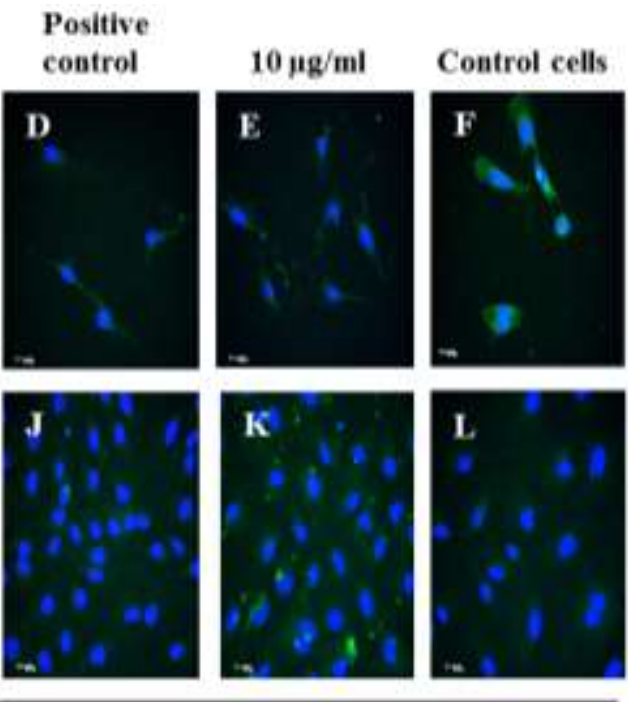

HIF-1 $\alpha$

Figure 4. Effects of the QG HAE on the expression of MMP-14 (A, B, C, G, H, and I) and HIF-1a (D, E, F, J, K) in MC3T3-E1 preosteoblasts by immunofluorescence. Results indicate that MC3T3-E1 preosteoblasts treated with QG (10 $\mu \mathrm{g} / \mathrm{ml}$ ) showed increased expression of MMP-14 (H) and HIF-1a $(\mathrm{K})$ when compared to a positive control group (untreated) at $96 \mathrm{~h}(\mathrm{G}$ and $\mathrm{J}$ ). Cells with green immunofluorescence (white arrow) are visible on preosteoblasts treated with QG ( $\mathrm{H}$ and $\mathrm{K}$ ) and antibody control ( $\mathrm{C}$ and $\mathrm{F})$. Control cells (SaOS-2): the presence of primary antibody ( $\mathrm{C}$ and $\mathrm{F})$ and the absence of primary antibody ( $\mathrm{I}$ and $\mathrm{L}$ ). The nuclei were stained with DAPI (blue). Scale bar: $20 \mu \mathrm{m}$. $40 \mathrm{X}$ magnification.

\section{DISCUSSION}

In the present study, we found, by HPLC-DAD analysis of the ethanolic extract (EtOH) $70 \%$ of the QG leaves, flavonoids, and compounds derived from gallic acid. These classes of compounds have already been identified as having anti-inflammatory properties, among others $[4,5,6]$. The literature reveals that the leaf extract has flavonoids, alkaloids, saponins and tannins, and other flavonoid derivatives [23], which corroborates in part our findings.

When evaluating the effect of the extract on cell viability, it was observed a reduction of the viability for both cell lines (NIH/3T3 fibroblasts and MC3T3-E1 preosteoblasts), exposed to a higher concentration of the extract $(10 \mu \mathrm{g} / \mathrm{ml})$ within 72 and $96 \mathrm{~h}$ after treatment, but without total cell death. These results suggest a clear negative effect of the extract on cellular viability, considering a control group (no treatment).

The results of the immunofluorescence assay revealed, through a qualitative analysis, that the QG HAE increased the expression of MMP-14 and HIF-1 $\alpha$, in both cell types. HIF-1 $\alpha$ is an important molecule involved in the response to hypoxia conditions and its activation is essential to act in the tissue repair and regeneration processes [24, 25]. The relationship between the HIF pathway and MMPs is quite close, since MMPs actively participate in all phases of angiogenesis, starting with the initial degradation of the basement membrane until the final degradation of excess vasculature [26, 27, 28]; among the MMPs involved in the process, MMP-14, the target molecule of this research, was identified as a key factor [29, 30]. Given the aforementioned, we can assume that the increased expression of MMP-14 and HIF-1 $\alpha$, a fact (results) observed in our present study, could be beneficial in a situation of tissue repair and such an effect can be associated with the components of the plant. It is worth mentioning that we do not use the individual components of the QG leaf extract, which leads us to believe that the observed effects may be due to the interaction between two or more components. The information we have available so far is that the components present in the plant are known to exhibit various therapeutic properties [3,4,31,32].

Sheng-Teng Huang et al. (2018) [33] showed that the expression of MMP-14, the main transmembrane MMP for angiogenesis, increased significantly after treatment with Drynaria fortunei, a species of fern native to East Asia used in traditional Chinese medicine for treat common injuries, including bone fractures and bruises. Flavonoids, phenylpropanoids and triterpenes are the main compounds present in $D$. fortunei. In another studies, it was demonstrated that quercetin, a natural flavonoid, activates HIF-1 $\alpha$ at all stages of its activation pathway, modulating the stability and activity of HIF-1 $\alpha$ in endothelial cells [34, 35]. The main 
hypothesis of the model of action of quercetin in the regulation of HIF-1 $\alpha$ activity is based on its ability to act as a chelator of the iron ion, which currently acts as a cofactor for HIF-Prolyl Hydroxylase [36, 37]. The enzyme HIF-Prolyl Hydroxylase, inhibited by quercetin, is a key enzyme in the degradation of HIF-1a. Thus, quercetin promotes an increase in the activity of HIF-1 $\alpha[37,38]$. Besides, report showed the quercetin action on inhibiting cell proliferation $[39,40]$. These data corroborate our findings, since we found an inhibition of cell viability and overexpression of MMP-14 and HIF-1 $1 \alpha$ in the groups treated with the QG extract. Additional research is needed to study the potential of $Q G$ as a modulator of MMP-14 and HIF-1a expression.

In summary, this study showed that the QG leaf extract has the potential to increase the expression of HIF-1 $\alpha$ and MMP-14, molecules that are essential for the tissue repair process.

\section{CONCLUSION}

We conclude that the hydroalcoholic extract of the leaves of Qualea grandiflora has compounds with proven therapeutic activities which modulate the expression of MMP-14 and HIF-1a.

Funding: This work was supported by the São Paulo Research Foundation - FAPESP under grants n.\#2014/20656-0 and \#2014/05234-2.

Conflicts of Interest: The authors declare no conflict of interest related to this study.

\section{REFERENCES}

1. Ratter JA, Bridgewater S, Ribeiro JF. Analysis of the floristic composition of the Brazilian cerrado vegetation III: comparison of the woody vegetation of 376 areas. Edinb. j. bot. 2003; 60 (1):57-109.

2. Hiruma-Lima CA, Santos LC, Kushima H, Pellizzon CH, Silveira GG, Vasconcelos PC, et al. Qualea grandiflora, a Brazilian "Cerrado" medicinal plant presents an important antiulcer activity. J Ethnopharmacol. 2006; 104 (1-2):20714.

3. Gaspi FO, Foglio MA, Carvalho JE, Moreno RA. Pharmacological activities investigation of crude extracts and fractions from Qualea grandiflora Mart. J Ethnopharmacol. 2006; 107 (1): 19-24.

4. Santos FV, Nasser AL, Biso FI, Moreira LM, Santos VJ, Vilegas W, et al. Genotoxicity of polar and apolar extracts obtained from Qualea multiflora and Qualea grandiflora. J Ethnopharmacol. 2011; 138 (1): 105-10.

5. Costa ES, Hiruma-Lima CA, Lima EO, Sucupira GC, Bertolin AO, Lolis SF, et al. Antimicrobial activity of some medicinal plants of the Cerrado, Brazil. Phytother Res. 2008; 22 (5): 705-7.

6. Cerrado: espécies vegetais úteis [Internet] - [cited 2019 Oct 25]. Available from: https://www.bdpa.cnptia.embrapa.br.

7. Carnevale Neto FC, Pilon AC, Silva DHS, Bolzani VS, Castro-gamboa I. Vochysiaceae: secondary metabolites, ethnopharmacology and pharmacological potential. Phytochem Rev. 2011; 10:413.

8. Carnevale Neto F, Siquitelli CD, Pilon AC, Silva DHS, Bolzani VS, Castro-Gamboa I. Dereplication of phenolic derivatives of Qualea grandiflora and Qualea cordata (Vochysiaceae) using liquid chromatography coupled with ESI-QToF-MS/MS. J. Braz. Chem. Soc. 2013; 24:758-64.

9. Karas D, Ulrichová J, Valentová K. Galloylation of polyphenols alters their biological activity. Food Chem Toxicol. 2017; 105:223-40.

10. Perez-Vizcaino F, Fraga CG. Research trends in flavonoids and health. Arch Biochem Biophys. 2018; 646:107-12.

11. Zigrino P, Brinckmann J, Niehoff A, Lu Y, Giebeler N, Eckes B, et al. Fibroblast-Derived MMP-14 Regulates Collagen Homeostasis in Adult Skin. J Invest Dermatol. 2016; 136 (8):1575-83.

12. Darby IA, Hewitson TD. Hypoxia in tissue repair and fibrosis. Cell Tissue Res. 2016; 365:553-62.

13. Li Y, Sun R, Zou J, Ying Y, Luo Z. Dual Roles of the AMP-Activated Protein Kinase Pathway in Angiogenesis. Cells. 2019; 8(7):752.

14. Sheikh AM, Yano S, Mitaki S, Haque MA, Yamaguchi S, Nagai A. A Mesenchymal stem cell line (B10) increases angiogenesis in a rat MCAO model. Exp Neurol. 2019; 311:182-93.

15. Wan C, Gilbert SR, Wang Y, Cao X, Shen X, Ramaswamy G, et al. Activation of the hypoxia-inducible factor-1alpha pathway accelerates bone regeneration. Proc Natl Acad Sci U S A. 2008; 15;105(2):686-91.

16. Oliveira FA, Matos AA, Matsuda SS, Buzalaf MA, Bagnato VS, Machado MAAM, et al. Low level laser therapy modulates viability, alkaline phosphatase and matrix metalloproteinase-2 activities of osteoblasts. J Photochem Photobiol B. 2017; 169:35-40. 
17. Piacenti-Silva M, Matos AA, Paulin JV, Alavarce RAS, Oliveira RC, Graeff CFO. Biocompatibility investigations of synthetic melanin and melanin analogue for application in bioelectronics. Polym Int. 2016; 65 (11):1347-54.

18. Machado AC, Souza LP, Saldanha LL, Pieroni LG, Matos AA, Oliveira FA, et al. "Aroeira" (Myracrodruon urundeuva) methanol extract: the relationship between chemical compounds and cellular effects. Pharm Biol. 2016 ; 54 (11) :2737-41.

19. Mosmann T. Rapid colorimetric assay for cellular growth and survival. Application to proliferation and cytotoxicity assays. J Immunol Methods. 1983; 65:55-63.

20. Pacheco PS, Oliveira FA, Oliveira RC, Sant'ana AC, Rezende ML, Greghi SL, et al. Laser phototherapy at high energy densities do not stimulate pre-osteoblast growth and differentiation. Photomed Laser Surg. 2013 ; 31 (5): 225-9.

21. Futamura N, Nishida Y, Urakawa H, Kozawa E, Ikuta K, Hamada S, et al. EMMPRIN co-expressed with matrix metalloproteinases predicts poor prognosis in patients with osteosarcoma. Tumour Biol. 2014; 35:5159-65.

22. Wei X, Wang C, Ma C, Sun W, Li H, Cai Z. Long noncoding RNA ANRIL is activated by hypoxia-inducible factor-1a and promotes osteosarcoma cell invasion and suppresses cell apoptosis upon hypoxia. Cancer Cell Int. 2016 ; 16:73.

23. Lima Neto GA, Kaffashi S, Luiz WT, Ferreira WR, Dias da Silva YSA, Pazin GV, et al. Quantificação de metabólitos secundários e avaliação da atividade antimicrobiana e antioxidante de algumas plantas selecionadas do Cerrado de Mato Grosso. Rev. Bras. PI. Med. 2015; 17 (4):1069-77.

24. Tomlinson RE, Silva MJ. HIF-1a regulates bone formation after osteogenic mechanical loading. Bone. 2015; 73:98104.

25. Stegen S, Deprez S, Eelen G, Torrekens S, Van Looveren R, Goveia J, et al. Adequate hypoxia inducible factor 1a signaling is indispensable for bone regeneration. Bone. 2016; 87:176-86.

26. Yang Y, Rosenberg GA. Matrix metalloproteinases as therapeutic targets for stroke. Brain Res. 2015; 1623:30-38.

27. Kachgal S, Carrio B, Janson IA, Putnam AJ. Bone marrow stromal cells stimulate an angiogenic program that requires endothelial MT1-MMP. J Cell Physiol. 2012;227(11):3546-55.

28. Accorsi-Mendonça T, Paiva KB, Zambuzzi WF, Cestari TM, Lara VS, Sogayar MC, et al. Expression of matrix metalloproteinases-2 and -9 and RECK during alveolar bone regeneration in rat. J Mol Histol. 2008; 39:201-8.

29. Genís L, Gálvez BG, Gonzalo P, Arroyo AG. MT1-MMP: Universal or particular player in angiogenesis? Cancer Metastasis Rev. 2006; 25:77-86.

30. Paiva KB, Granjeiro JM. Bone tissue remodeling and development: focus on matrix metalloproteinase functions. Arch Biochem Biophys. 2014; 561:74-87.

31. Magalhães KDN, Guarniz WAS, Sá KM, Freire AB, Monteiro MP, Nojosa RT, et al. Medicinal plants of the Caatinga, northeastern Brazil: Ethnopharmacopeia (1980-1990) of the late professor Francisco José de Abreu Matos. J Ethnopharmacol. 2019; 237:314-53.

32. Nasser AL, Carli CB, Rodrigues CM, Maia DC, Carlos IZ, Eberlin MN, et al. Identification of ellagic acid derivatives in methanolic extracts from Qualea species. Z Naturforsch C. 2008; 63 (11-12):794-800.

33. Huang ST, Chang CC, Pang JS, Huang HS, Chou SC, Kao MC, et al. Drynaria fortunei Promoted Angiogenesis Associated With Modified MMP-2/TIMP-2 Balance and Activation of VEGF Ligand/Receptors Expression. Front Pharmacol. 2018; 21;9:979.

34. Wilson WJ, Poellinger L. The dietary flavonoid quercetin modulates HIF-1 alpha activity in endothelial cells. Biochem Biophys Res Commun. 2002; 293(1):446-50.

35. Tumova S, Kerimi A, Williamson G. Long term treatment with quercetin in contrast to the sulfate and glucuronide conjugates affects HIF1a stability and Nrf2 signaling in endothelial cells and leads to changes in glucose metabolism. Free Radic Biol Med. 2019; 137:158-68.

36. Park SS, Bae I, Lee YJ. Flavonoids-induced accumulation of hypoxia-inducible factor (HIF)-1alpha/2alpha is mediated through chelation of iron. J Cell Biochem. 2008; 103(6):1989-98.

37. Jeon H, Kim H, Choi D, Kim D, Park SY, Kim YJ, Kim YM, Jung Y. Quercetin activates an angiogenic pathway, hypoxia inducible factor (HIF)-1-vascular endothelial growth factor, by inhibiting HIF-prolyl hydroxylase: a structural analysis of quercetin for inhibiting HIF-prolyl hydroxylase. Mol Pharmacol. 2007; 71(6):1676-84.

38. Bach A, Bender-Sigel J, Schrenk D, Flügel D, Kietzmann T. The antioxidant quercetin inhibits cellular proliferation via HIF-1-dependent induction of p21WAF. Antioxid Redox Signal. 2010; 13(4):437-48. 
39. Triantafyllou A, Liakos P, Tsakalof A, Chachami G, Paraskeva E, Molyvdas PA, Georgatsou E, Simos G, Bonanou $\mathrm{S}$. The flavonoid quercetin induces hypoxia-inducible factor-1alpha (HIF-1alpha) and inhibits cell proliferation by depleting intracellular iron. Free Radic Res. 2007; 41(3):342-56.

40. Stegen S, van Gastel N, Carmeliet G. Bringing new life to damaged bone: The importance of angiogenesis in bone repair and regeneration. Bone. 2015; 70:19-27.

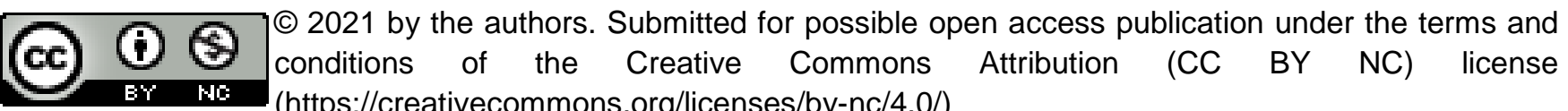
(https://creativecommons.org/licenses/by-nc/4.0/) 